\title{
Erratum to: HN protein of Newcastle disease virus causes apoptosis in chicken embryo fibroblast cells
}

\author{
P. V. Ravindra - Ashok K. Tiwari - Bhaskar Sharma - Yogendra Singh Rajawat • \\ Barkha Ratta $\cdot$ Sudesh Palia $\cdot$ N. R. Sundaresan $\cdot$ Uttara Chaturvedi \\ Arunakumar Gangaplara $\cdot$ Kantaraja Chindera $\cdot$ Meeta Saxena $\cdot$ \\ P. K. Subudhi $\cdot$ Anant Rai $\cdot$ R. S. Chauhan
}

Published online: 2 July 2014

(C) Springer-Verlag Wien 2014

Erratum to: Arch Virol (2008) 153:749-754

DOI 10.1007/s00705-008-0057-2

The author name G. B. Aruna Kumar has to be corrected to Arunakumar Gangaplara.

The online version of the original article can be found under doi:10.1007/s00705-008-0057-2.

P. V. Ravindra · A. K. Tiwari $(\bowtie) \cdot$ Y. S. Rajawat · B. Ratta ·

S. Palia · N. R. Sundaresan - U. Chaturvedi - A. Gangaplara ·

K. Chindera $\cdot$ P. K. Subudhi $\cdot$ A. Rai

Division of Animal Biotechnology, Indian Veterinary Research

Institute, Izatnagar 243122, India

e-mail: aktiwari63@yahoo.com

B. Sharma $\cdot$ M. Saxena

Division of Animal Biochemistry,

Indian Veterinary Research Institute,

Izatnagar 243122, India

R. S. Chauhan

Centre for Animal Disease Research and Diagnosis,

Indian Veterinary Research Institute, Izatnagar 243122, India 